\title{
Using an Image-Intensifier in Astronomy
}

\author{
Thierry Midavaine
}

Appt. 1199, 142 Bd. Masséna, F-75013 Paris, France

\begin{abstract}
The use of an RTC XX 1390 second-generation intensifier (which consists of a S20R photocathode, a micro-channel plate and a screen) was described. In visual work, very faint objects become visible. Photographically, an 18th-magnitude object has been detected through a layer of cirrus. The effective focal length used was $20 \mathrm{~m}$, giving a resolution of 1 arcsecond, thanks to the short exposure times needed. With a Celestron C8 telescope, the coma of Comet Halley was photographed with 2-second exposures, allowing transitory phenomena to be detected. Used in conjunction with video techniques, high time-resolution images could be obtained, opening up the possiblity of new forms of observation of faint objects.
\end{abstract}

\section{References}

1. Caron, R., Koutchmy, S., Sarazin, M.: "A study of disconnection velocities in the plasma tail of $\mathrm{P} / \mathrm{Halley",} \mathrm{paper} \mathrm{presented} \mathrm{at} \mathrm{this} \mathrm{Colloquium}$

2. Maley, P.D.: "Achievements in astronomical video data collection", paper presented at this Colloquium

3. Dahlmark, L., "Searching for variables, and constructing a slit-less spectroscope", paper presented at this Colloquium

4. Midavaine, T.: in Astronomie: le guide de l'observateur, ed. Martinez, P., Vol. 2, Chap. XIX, Paris, 1987

5. Mauro, J.A., ed.: Optical Engineering Handbook, General Electric Co., Syracuse, N.Y., 1966

6. Midavaine, T.: Observations et Travaux, in press

\section{Amateur Polarimetric Research}

\section{Dietmar Böhme}

DDR-4851 Nessa 11, PSF 93, GDR

\section{Abstract}

The construction of both single- and twin-channel polarimeters was described. Refractors are suitable for this form of work, and Cassegrains may be used, but Newtonians are not recommended, because of the polarization it introduces. A summary of objects and their degree of polarization was given. Examples of variation in the amount of polarization and its correlation with visual observations of $\mu$ Cephei were given.

\section{References}

A full account (in German) has been published in Sterne und Weltraum, 25, p.544-9, 1986 Observations of $\mu$ Cep are given in Die Sterne, 60, p.315-8, 1984 